\title{
Navigating COVID-19 in the developing world
}

\section{Bridget Hodkinson ${ }^{1}$ (D) Prasun Singh ${ }^{1} \cdot$ Ayanda Gcelu $^{1} \cdot$ Wilson Bautista Molano ${ }^{2} \cdot$ Guillermo Pons-Estel $^{3,4}$. Deshiré Alpízar-Rodríguez ${ }^{5}$}

Received: 14 April 2020 / Revised: 2 May 2020 / Accepted: 5 May 2020

(C) International League of Associations for Rheumatology (ILAR) 2020, corrected publication 2020

The severe acute respiratory syndrome coronavirus 2 (SARSCoV-2) has been declared a pandemic and a global public health emergency by the World Health Organization. This condition began in China in December 2019, was exported by international travellers and is now spreading by community transmission with cases reported in every country around the world. Over 3 million people are infected as of 2 May 2020, with over 240,000 reported deaths [1]. The case fatality rate is estimated at $1-5 \%$, and no effective treatment has been clearly demonstrated for patients severely affected by the disease caused by SARS-CoV-2, named COVID-19.

Rheumatologists and clinicians world over are scrambling to advise and protect their patients from this infection. We know that patients with rheumatic and musculoskeletal diseases (RMDs), particularly those with systemic autoimmune diseases, are at increased risk of infections due to the RMD itself and due to immunosuppressive agents including corticosteroids and conventional synthetic, biologic, biosimilar and targeted synthetic disease modifying antirheumatic drugs (DMARDs). At present, however, there is no evidence that patients with RMD or patients on immunosuppressants fare worse in the COVID-19 pandemic than any other patient [2].

Bridget Hodkinson

drbridget@gmail.com

1 Rheumatology, Department of Medicine, Groote Schuur Hospital and University of Cape Town, Cape Town, South Africa

2 University Hospital Fundación Santa Fé de Bogotá and Universidad El Bosque, Bogotá, Colombia

3 Centro Regional de Enfermedades Autoinmunes y Reumáticas (CREAR), Grupo Oroño, Rosario, Argentina

4 Research Unit, Sociedad Argentina de Reumatología, Buenos Aires, Argentina

5 Research Unit, Colegio Mexicano de Reumatología, Mexico City, Mexico
Current recommendations state that patients should continue their current RMD therapy, because a flare in disease activity may follow discontinuation of therapy. Such flares may result in an increased risk of infection, may require corticosteroid therapy and may need medical attention increasing the probability of being in contact with healthcare facilities and therefore with the virus $[3,4]$.

The antimalarial (AM) hydroxychloroquine (HCQ) and chloroquine (CQ) have demonstrated antiviral activity against severe SARS-CoV-2 in vitro and in small clinical studies [5, 6]. To date, however, no high-quality clinical data has shown clear benefit of AM, and a recent retrospective study failed to show that HCQ, either with or without azithromycin, reduced the risk of mechanical ventilation in patients hospitalized with COVID-19 [7]. Both HCQ and CQ are used by many RMD patients. Further studies will clarify the role of AM as prophylaxis or therapy in the COVID-19 pandemic, but our RMD patients should continue these therapies. In addition, tocilizumab is showing promise for the therapy of a severe COVID-19 cytokine release syndrome [8]. Additional information is needed in order to fully understand the utility of these interventions.

Low- and middle-income countries (LMICs) of the Southern hemisphere are bracing themselves for the SARSCoV-2 pandemic and are potentially facing worse outcomes and different challenges than the hard-hit developed world [9]. This may be due to the significant burden of noncommunicable diseases in LMIC, including cardiovascular illness, diabetes and lung disease, combined with the highest global prevalence of infections such as malaria, dengue, tuberculosis (TB) and HIV $[10,11]$. Studies demonstrate that HIV-infected persons with low CD4 counts are at greater risk for influenza infection and its complications including pneumococcal co-infection, longer hospital stays and increased mortality, as well as prolonged viral shedding [12-14]. Persons with pulmonary TB (PTB) are at increased risk of influenza-associated mortality [15]. However, there is currently no evidence that HIV positive patients have poor outcomes 
in the SARS-CoV-2 pandemic, even in areas of high HIV prevalence such as Thailand [16]. In fact, antiretroviral therapy used by HIV positive patients may be protective from COVID-19 infection or serious complications, and there is interest in using HIV antiretroviral therapy to treat severe COVID-19, although very recently lopinavir-ritonavir has shown no benefit [17]. Endemic diseases in LMIC countries may not only increase the burden of SARS-CoV-2 in these populations but may also cause false positive screening tests, especially for dengue. This situation may delay the diagnosis of COVID-19 and therefore increase the spread of the virus, because in most dengue cases, there are no warning signals and the follow-up is ambulatory [18].

The brunt of most acute and chronic diseases is borne by the poor, and it is very likely that poor socio-economic status will impact on spread and outcomes of the SARSCoV-2 epidemic. Overcrowded living conditions, food insecurity and poor access to basic amenities including water, congested public transport and shortage of personal protective equipment (PPE) for doctors, nurses and medical staff and SARS-CoV-2 infected patients all favour viral spread. Political disruption and poor education with lack of insight into the urgency of conforming to social distancing and lockdown measures may also hamper containment strategies. Care of patients with severe COVID-19 is challenging where healthcare capacities are already stretched thin, with a shortage of hospital beds ( $>12$ per 1000 population in much of Europe vs 1-2 in many LMIC), intensive care facilities (some European countries have 29 beds per 100,000 population, 35 in the USA and 5 or less in many LMIC countries), PPE and insufficient medical personnel (there are 2.7 physicians per 10,000 population in Africa and parts of South America compared with 21.5 in North Americas and 32.1 in Europe) [19-21].

Apart from its direct effects, the SARS-CoV-2 pandemic will bring chaos to fragile healthcare systems in LMIC. Currently, the day to day running of clinic services for chronic conditions including rheumatology outpatient clinics has stopped, jeopardizing new and existing patients' access to consultations, procedures and medication for months to come. Communications with our RMD patients is suboptimal with inadequate telemedicine platforms operational to date. In addition, both HCQ and CQ are now in short supply for patients taking it for RMD indications, as it has been snatched up for prophylaxis and therapy of COVID illness. Even once clinical services resume, the catch-up will be calamitous. We have seen how the recent Ebola epidemic greatly undermined malaria control efforts, resulting in an estimated 1 million malaria cases seen in West Africa in 2014 [22]. Similarly, the analysis of historic data shows that during the major influenza pandemics of 1889 and 1918, mortality due to TB significantly increased [23]. In Latin America, COVID-19 infection is an additional challenge for the health systems and economies where recent Zika and Chikungunya outbreaks have had significant impact [24]. The economic consequences of the COVID-19 pandemic are likely to hit LMIC hard, pushing many patients and their families below the breadline and shrinking healthcare resources.

Thus far, Southern hemisphere countries where many LMIC lie are not as severely affected by the virus as their Northern high and upper middle-income counterparts. Because of limited testing, a consequence of resource constraints, the actual number of cases in LMIC is likely much higher than reported. However, even LMIC countries with more than 1000 confirmed infections have not yet reported the massive mortalities seen in the North. One may argue that the time between symptom onset and death ranges from 2 to 8 weeks and that Southern hemisphere countries are 4 to 8 weeks behind the Northern hemisphere [25].

The developing world may have some mitigating factors against the COVID-19 pandemic. The first is forewarning and a small window of preparation time. As the pandemic spreads, LMIC can study and learn from the successes and mistakes of the Northern hemisphere. Measures to contain transmission include discontinuing international travel, educating the public, restricting gatherings and timeously locking down all nonessential activities and planning clinical services for severe COVID-19 cases. Secondly, the virus seems to survive better in cold, dry weather with reduced ultraviolet light. The warm climate and the summer season in the Southern hemisphere may offer some protection. Age, a poor prognostic factor in COVID-19 disease, favours LMIC where less than 5 or $10 \%$ of the population is over 65 years, compared with $25-30 \%$ in Europe [26]. Genetic factors may also influence susceptibility, symptoms and outcome. The angiotensin-converting enzyme 2 (ACE2) gene encodes the cell-entry receptor of both SARSCoV and SARS-CoV-2 [27, 28]. Polymorphisms in the ACE gene, associated with essential hypertension, are described in Africa and South America [29, 30]. Although very recent work has shown no evidence of ACE2 coronavirus bindingresistant mutants in different populations, further studies are needed [31]. Many LMIC countries remember well the lessons learned during SARS in 2003 and pandemic influenza in 2009. Protocols already developed during these crises, including laboratory and patient management, were designed and implemented in a scenario of limited resources. The protocols and previous experience with infectious diseases may be useful in this challenging situation [32].

Another potent advantage LMIC may have is resilience. Man versus nature is not a new battle here. Healthcare workers and patients have survived and often thrived through many challenges, including the ravages of infectious epidemics and the raw face of resource constraints. Rather than being misconstrued as "clinical deserts", LMIC have clinicians with bedside expertise and experience in triaging and making difficult therapeutic decisions frequently without laboratory or 
radiological investigations. In these COVID-19 times, clinical skills and experience working in very poorly resourced settings may be a major weapon in the armamentarium of healthcare providers. Images and video clips in the press from Italy and New York showing make-shift emergency rooms, beds on the floor and queues of desperately sick people waiting for care are familiar daily situations for many healthcare workers in LMIC.

The SARS-CoV-2 pandemic may be an opportunity to innovate. As seen in the SARS epidemic, this crisis can drive advances in undergraduate medical education [33]. With suspended classes, distant online teaching and learning including live-streamed webinars, video-based learning content, etextbooks and group chats accompanied by online assessments to track student performance and monitor retention is taking place. For clinical students, as an alternative to real patient interactions, virtual patient platforms have been successfully used to teach and assess diagnostic skills [34]. To facilitate this, academic institutions must urgently focus on the availability of infrastructure, connectivity and equipment for learners and educators, frequently in short supply in LMIC. This should be seen as an investment, laying the foundation for more efficient medical teaching in the future.

We have incentive to improve telemedicine platforms, fortify patient support groups, strengthening collaborative work and continue research registries including the recently formed international COVID-19 Global Rheumatology Alliance (https://rheum-COVID.org/). This virus can bring us closer together and can highlight our similarities, strengths and connections. Unprecedented generous donations from private companies or individuals to assist small businesses and their employees affected by the coronavirus pandemic are a remarkable step towards reducing the gap between rich and poor in LMIC [35]. While LMIC focus on providing essential services while keeping frontline care providers safe, we look to surviving this pandemic and its aftermath with resilience and innovation.

\section{Compliance with ethical standards}

Disclosures None.

\section{References}

1. World Health Organisation. Coronavirus disease Pandemic. https:// www.who.int/emergencies/diseases/novel-coronavirus-2019. Accessed

2. D'Antiga L (2020) Coronaviruses and immunosuppressed patients. The facts during the third epidemic. Liver Transpl Mar 20. https:// doi.org/10.1002/lt.25756

3. Venerito V, Lopalco G, Iannone F (2020) COVID-19, rheumatic diseases and immunosuppressive drugs: an appeal for medication adherence. Rheumatol Int 40(5):827-828
4. Favalli EG, Ingegnoli F, De Lucia O, Cincinelli G, Cimaz R, Caporali R (2020) COVID-19 infection and rheumatoid arthritis: faraway, so close! Autoimmun Rev 19(5):102523

5. Yao X, Ye F, Zhang M, Cui C, Huang B, Niu P et al (2020) In vitro antiviral activity and projection of optimized dosing design of hydroxychloroquine for the treatment of severe acute respiratory syndrome coronavirus 2 (SARS-CoV-2). Clin Infect Dis. https:// doi.org/10.1093/cid/ciaa237

6. Yazdany J, Kim AHJ (2020) Use of hydroxychloroquine and chloroquine during the COVID-19 pandemic: what every clinician should know. Ann Intern Med Mar 31. https://doi.org/10.7326/ M20-1334

7. Magagnoli J, Narendran S, Pereira F, Cummings T, Hardin JW, Sutton SS, Ambati J. Outcomes of hydroxychloroquine usage in United States veterans hospitalized with Covid-19. medRxiv 2020.04.16.20065920. https://doi.org/10.1101/2020.04.16.20065920

8. Lu CC, Chen MY, Chang YL (2020) Potential therapeutic agents against COVID-19: what we know so far. J Chin Med Assoc. https://doi.org/10.1097/JCMA.0000000000000318

9. Gates B (2020) Responding to Covid-19 - a once-in-a-century pandemic? N Engl J Med 382(18):1677-1679

10. Mayosi BM, Flisher AJ, Lalloo UG, Sitas F, Tollman SM, Bradshaw D (2009) The burden of noncommunicable diseases in South Africa. Lancet. 374(9693):934-947

11. Murray CJ, Ortblad KF, Guinovart C, Lim SS, Wolock TM, Roberts DA et al (2014) Global, regional, and national incidence and mortality for HIV, tuberculosis, and malaria during 1990 2013: a systematic analysis for the Global Burden of Disease Study 2013. Lancet 384(9947):1005-1070

12. Cohen C, Moyes J, Tempia S, Groom M, Walaza S, Pretorius M et al (2013) Severe influenza-associated respiratory infection in high HIV prevalence setting, South Africa, 2009-2011. Emerg Infect Dis 19(11):1766-1774

13. Lin JC, Nichol KL (2001) Excess mortality due to pneumonia or influenza during influenza seasons among persons with acquired immunodeficiency syndrome. Arch Intern Med 161(3):441-446

14. von Mollendorf C, Hellferscee O, Valley-Omar Z, Treurnicht FK, Walaza S, Martinson NA et al (2018) Influenza viral shedding in a prospective cohort of HIV-infected and uninfected children and adults in 2 provinces of South Africa, 2012-2014. J Infect Dis 218(8):1228-1237

15. Walaza S, Cohen C, Nanoo A, Cohen AL, McAnerney J, von Mollendorf C et al (2015) Excess mortality associated with influenza among tuberculosis deaths in South Africa, 1999-2009. PLoS One 10(6): 0129173

16. Joob B, Wiwanitkit V (2020) SARS-CoV-2 and HIV. J Med Virol. https://doi.org/10.1002/jmv.25782

17. Cao B, Wang Y, Wen D, Liu W, Wang J, Fan G et al (2020) A trial of lopinavir-ritonavir in adults hospitalized with severe Covid-19. N Engl J Med 382(19):1787-1799

18. Saavedra-Velasco M, Chiara-Chilet C, Pichardo-Rodriguez R, Grandez-Urbina A, Inga Berrospi F (2020) Coinfección entre dengue y COVID-19: Necesidad de abordaje en zonas endémicas. Revista De La Facultad De Ciencias Médicas De Córdoba 77:52-54

19. Mody GM (2017) Rheumatology in Africa-challenges and opportunities. Arthritis Res Ther 19(1):49

20. Rhodes A, Ferdinande P, Flaatten H, Guidet B, Metnitz PG, Moreno RP (2012) The variability of critical care bed numbers in Europe. Intensive Care Med 38(10):1647-1653

21. World Health Organisation. Global Health Observatory Data https://www.who.int/gho/publications/world_health_statistics/en/. Accessed 6 April 2020

22. Wang J, Xu C, Wong YK, He Y, Adegnika AA, Kremsner PG et al (2020) Preparedness is essential for malaria-endemic regions during the COVID-19 pandemic. Lancet 395(10230):1094-1096 
23. Zurcher K, Zwahlen M, Ballif M, Rieder HL, Egger M, Fenner L (2016) Influenza pandemics and tuberculosis mortality in 1889 and 1918: analysis of historical data from Switzerland. PLoS One. 11(10): $\mathrm{e} 0162575$

24. Cardona-Ospina JA, Villamil-Gomez WE, Jimenez-Canizales CE, Castaneda-Hernandez DM, Rodriguez-Morales AJ (2015) Estimating the burden of disease and the economic cost attributable to chikungunya, Colombia, 2014. Trans R Soc Trop Med Hyg. 109(12):793-802

25. World Health Organisation. Report of the WHO-China Joint Mission on Coronavirus Disease 2019. https://publicintelligence. net/who-china-mission-covid-19/. Accessed 6 April 2020

26. United Nations. World Population Prospects 2019 https:// population.un.org/wpp/Maps/. Accessed 6 April 2020

27. Li W, Moore MJ, Vasilieva N, Sui J, Wong SK, Berne MA et al (2003) Angiotensin-converting enzyme 2 is a functional receptor for the SARS coronavirus. Nature. 426(6965):450-454

28. Yang JM, Meng X, Xue F, Zhang Y, Zhang C (2020) ACE2 in the context of 2019-nCoV infection: friend or foe? Zhonghua Xin Xue Guan Bing Za Zhi 48(0):E012

29. Mengesha HG, Petrucka P, Spence C, Tafesse TB (2019) Effects of angiotensin converting enzyme gene polymorphism on hypertension in Africa: a meta-analysis and systematic review. PLoS One. 14(2):e0211054

30. Pinheiro DS, Santos RS, Jardim P, Silva EG, Reis AAS, Pedrino GR et al (2019) The combination of ACE I/D and ACE2 G8790A polymorphisms revels susceptibility to hypertension: a genetic association study in Brazilian patients. PLoS One 14(8):e0221248
31. Cao Y, Li L, Feng Z, Wan S, Huang P, Sun X et al (2020) Comparative genetic analysis of the novel coronavirus (2019$\mathrm{nCoV} / \mathrm{SARS}-\mathrm{CoV}-2)$ receptor ACE2 in different populations. Cell Discov. 6:11

32. Rodriguez-Morales AJ, Gallego V, Escalera-Antezana JP, Mendez CA, Zambrano LI, Franco Paredes C et al (2020) COVID-19 in Latin America: the implications of the first confirmed case in Brazil. Travel Med Infect Dis. https://doi.org/10.1016/j.tmaid. 2020.101613

33. Patil NG, Chan Y, Yan H (2003) SARS and its effect on medical education in Hong Kong. Med Educ 37(12):1127-1128

34. Kononowicz AA, Woodham LA, Edelbring S, Stathakarou N, Davies D, Saxena N et al (2019) Virtual patient simulations in health professions education: systematic review and meta-analysis by the digital health education collaboration. J Med Internet Res 21(7):e14676

35. Motsepe family \& associates join Rupert and Oppenheimer families in donating R1bn to deal with COVID-19 pandemic. CNBC Africa. 2020. https://www.forbesafrica.com/billionaires/2020/03/30/ motsepe-family-associates-join-rupert-andoppenheimer-familiesin-donating-r1-billion-to-deal-with-covid-19-pandemic/. Accessed 6 April 2020

Publisher's note Springer Nature remains neutral with regard to jurisdictional claims in published maps and institutional affiliations. 